Jokikokko, K. \& Uitto, M. 2017. The significance of emotions in Finnish teachers' stories about their intercultural learning. Pedagogy, Culture \& Society 25(1), 15-29. http://dx.doi.org/10.1080/14681366.2016.1201128

\title{
The Significance of Emotions in Finnish Teachers' stories about their intercultural Learning
}

\author{
Katri Jokikokko \& Minna Uitto \\ Faculty of Education, University of Oulu
}

The need to improve teachers' abilities to respond to the needs of diverse students has been widely acknowledged. To acquire these abilities teachers need ongoing reflection and possibilities to learn in practice in various contexts. However, earlier research has not extensively theorised teachers' intercultural learning as a holistic life-long learning process. This article discusses teachers' intercultural learning as a lifelong process in which emotions play a significant role. The article is based on the findings of an analysis of biographical interviews with ten Finnish teachers. The research question of the article is: How do teachers describe the meaning of emotions for their intercultural learning? The findings present four ways that the emotional dimension of intercultural learning was present in the teachers' stories: emotions shook the teachers' values and perspectives, emotions triggered action, the teachers' own feelings of otherness enabled sensitivity towards others, and the emotional climate supported the teachers' intercultural learning. Finally, the article discusses the pedagogical conditions for teachers' intercultural learning as an emotional process.

Keywords: emotions, intercultural learning, intercultural pedagogy, narrative research, teacher education, teachers 


\section{Introduction}

The need to improve teachers' abilities to respect and respond to diversity in a way that creates fairer learning opportunities for diverse students has been widely acknowledged by researchers in the field of intercultural and multicultural education (Gay 2000; Nieto 2005; Sleeter 2010). To acquire the intercultural skills and mindset, teachers need ongoing practice, reflection and various opportunities to learn in new and changing contexts. In this article, 'diversity' is understood broadly: it does not refer only to ethnic or linguistic background or 'immigrant students'; diversity is seen as differences that are part of us all, part of our identities (e.g. worldview, religion, age, gender, physical abilities, sexual orientation and socioeconomic background among others). These categories of difference are often more fluid than fixed (e.g. Nieto 2002; Parekh 2006), which makes diversity something that is impossible to examine from an objective, scientific viewpoint.

Teachers' intercultural learning is a highly topical issue, especially in European countries (including Finland), as Europe is experiencing one of the most significant influxes of migrants and refugees in its history. Thus, there definitely is a great need for teachers to develop more culturally sensitive attitudes and practices that would enable them to embrace people whose values and beliefs differs from their own. Teachers are the key agents in supporting diverse students in finding their place in society. At the same time, educational reforms focusing on 'standards, 'outcomes' and 'impacts' are gaining ground fast both in schools and teacher education (e.g. Hattie 2012). From the perspective of diversity this can be a problematic trend, as focusing on standards based ideas easily diminish the significance of diversity. Thus, this article also speak against standard-oriented educational trends and emphasises 
that teachers should be provided with possibilities, spaces and time to construct and reflect their identities: this is necessary for intercultural learning.

Prior research has often viewed intercultural learning as a process which occurs when a person visits another country or moves to live or work in another country and encounters cultural differences (e.g. Bennett 1993; Landis, Bennett and Bennet 2004; Taylor 1994). There are various developmental models in which intercultural attitudes, knowledge and skills help an individual to progress toward effective and appropriate behaviour in intercultural situations (Bennett 1993; Deardorff 2006). This article takes a different stance; it approaches intercultural learning as a lifelong process that is often informal. It presents a thematic analysis of the biographical stories of ten Finnish teachers and discusses their intercultural learning in the context of their lives and work by focusing on those emotionally loaded moments and experiences that made teachers critically reflect their values and ideals related to diversity and wonder 'who we actually are?' (c.f. Connelly and Clandinin, 1999; Elbaz-Luwisch, 2010).

Intercultural learning in the context of teachers' lives and work can be understood in different ways: it can be related to learning didactic skills for working 'effectively' in multicultural classrooms with a focus on communication and acquisition of knowledge from another country or culture (Byram 1997). However, this article examines teachers' intercultural learning through the lens of critical pedagogy (e.g. Freire 1972; Nieto 2000; McLaren 2001; Sleeter 2001); it is learning to see, understand and address the complex inequitable, undemocratic and oppressive structures, practices, and social relations in education in order to create a more just school - and society - for all. Thus, this article views teachers' intercultural learning as closely linked to social justice and social change. Although understanding the 
structural inequities is important for a teacher, we also want to emphasise the importance of encountering the other in a respectful way as a substantial goal of intercultural learning.

The research that has acknowledged the role of emotions in intercultural/social justice issues has mainly focused on education and pedagogy, and not very much on the intercultural learning process itself (Britzman 1998; Boler 1999; Callahan 2004; Zembylas and Chubbuck 2009; Zembylas and McGlynn 2013). Thus, the previously mentioned authors do not often use the concept of intercultural learning as such, even though they refer to emotional and transformative processes related to social justice/intercultural education. Although this article focuses on the significance of emotions in teachers' intercultural learning, we want to highlight that emotions and reason cannot be separated (Zembylas and Vrasidas 2004) and that emotions are essential to rational thinking (Damasio 1999). However, the image of teachers as merely rational professionals who need to manage their emotions and also somewhat control their students' emotional expressions may still prevail e.g. in how pre-service and in-service teachers (and teacher educators) view emotions (Boler, 1999, Schutz and Zembylas, 2009). Furthermore, although research has long been interested in the role of emotion in learning (Jones 1968; Rogers 1969), there is a lack of previous research engaging emotions, particularly in intercultural learning and especially in the context of teachers' work (Uitto, Jokikokko and Estola 2015). However, some research exists on the crucial role of emotions in developing multicultural awareness and understanding in teacher education (Min Shim 2012; Taylor 2011; Wang 2012) as well as the significance of emotions in social justice education and teaching (Zembylas 2008; Zembylas and Chubbuck 2009, 2011; Zembylas and McGlynn 2013). Teachers' emotional responses to cultural differences have previously been 
discussed from the perspective of psychoanalysis and postcolonialism (Min Shim 2012; Taylor 2011). In these latter studies, the focus has mainly been on (white) preservice teachers' resistance towards differences and thus emotions seem to be more as a hindrance or a barrier to intercultural learning. By studying teachers' stories, this article aims to shed light on this rather under-researched field by studying how emotions are related to intercultural learning in different phases of teachers' life.

\section{Theoretical Framework}

When approaching teachers' intercultural learning, the central question is: how are we to understand the nature of teachers' work? In this article we approach teachers as reflective professionals who constantly evaluate and develop themselves and their work (Räsänen 2007). Although we see that teachers intercultural learning definitely relates to engaging ethically and responsibly with others, we also argue that in addition to this, teachers need to learn to broaden their cultural and global awareness and to take a critical and responsible perspective to global issues and especially issues of power and social justice (e.g. Andreotti and Souza 2011, Freire 1998; Giroux and McLaren 2001; Rizvi 2008; Taylor 2011). Instead of just 'knowing what to do' in a multicultural classroom, the reflection upon, and reconstruction of different ideas and practices becomes significant for a teacher, if we see that the teachers task is helping to create a more fair and just world in our classrooms and our everyday lives (Nieto, 2006; Zembylas and Chubbuck 2011).

It can be argued that, although there are different theoretical models that describe intercultural learning (Bennett 1993, 2009; Deardorff 2006), there is a need for more theoretical research to understand this learning process in depth. We approach teachers' intercultural learning as a life-long, holistic, both formal and 
informal process, in which emotions play a significant role. When defined this way, teachers' intercultural learning relates greatly to one's own identity. In the process of intercultural learning, teachers have to ask questions such as 'who am I as a teacher and a person' (c.f. Connely and Clandinin 1999; Heikkinen 1998). Emotions are inevitably present in such processes.

Emotions can be understood and defined differently. Many researchers who study emotions have agreed that emotions are not just (intra)individual, private and psychological phenomena, but are determined also by relationships and social contexts (e.g. Hargreaves 2001; Zembylas 2007). Zembylas, Charalambous, Charalambous and Kendeou (2011) define emotions as 'a socioculturally constituted public space, which also functions as a constitutive force for (trans)forming individuals, social interactions and power relations' (p. 334). This type of definition of emotions is meaningful in terms of intercultural learning, which can also be considered as a sociocultural learning process (Jokikokko 2010).

When discussing the role of emotions in intercultural learning, and particularly in teachers' biographical stories, the connection between values and emotions needs to be addressed as moral reflection can be seen to be at the core of intercultural learning: how we see the 'other' and the world around us, and how we relate to issues of discrimination and inequality. Our biographical experiences play a significant role when considering these questions. Solomon's emotion theory argues that emotions are indicators of moral beliefs (Solomon 1990). If someone feels strongly about something, it is likely to be important and meaningful for that person (Bullough 2009). Moral issues are often the ones that require learners to engage in demanding, and also discomforting, experiences. Unavoidably, such emotional examination can threaten people's core beliefs and create powerful (often negative) feelings such as 
anger, shame or resentment, which may inhibit or support the intercultural learning process (see Boler and Zembylas 2003; Zembylas 2007).

According to Bierema (2008), emotion must be valued as a valid and important aspect of change initiatives, not a force to be controlled and diminished. Thus, people should not view emotions in intercultural learning as destructive, but rather as a vital part of change. Any transformation begins with recognizing how one feels about social events (Freire 1998). Emotions structure how people create meaning in the face of change and help them navigate change. As Baumgartner and JohnsonBailey (2008) point out, even negative emotions can be a catalyst to delving deeper into underlying assumptions. Positive emotions can enhance the learning process.

Some researchers have pointed out that the mere existence of emotion does not necessarily lead to any change (or learning) (e.g. Zembylas 2008). In the context of teachers' intercultural learning, the central question is how to channel emotions into action in order to be able to encounter diversity in a meaningful way and disrupt unjust practices. Zembylas and Chubbuck (2009, see also Zembylas 2008; Zembylas and McGlynn 2013; Zembylas and Chubbuck 2011) have proposed the term critical emotional praxis to capture more specifically how emotions can be engaged as critical and transformative forces. They argue that 'critical emotional praxis consists in the ability to question emotionally charged, cherished beliefs, exposing how privileged positions and comfort zones inform the ways in which one recognizes what and how he or she has been taught to see and act (or not to see and act), and empowering different ways of being with and for the other' (p. 286). In this process, teachers are likely to experience a range of ambivalent emotions, such as fear, anxiety, courage and hope. Teachers need spaces to navigate these emotions and they can also use their 
emotional experiences as catalysts for developing socially just teaching (Zembylas and Chubbuck 2009, 2011).

\section{Research Context, Methodology and the Realization of the Research}

The research question for this article is:

How do teachers describe the meaning of emotions for their intercultural learning?

The teachers interviewed for this study had graduated from the intercultural teacher education (ITE) programme of the University of Oulu, Finland. The ITE programme began in 1994 and provides students with bachelor's (three years) and master's degrees (additional two years), including the primary teacher's diploma. ${ }^{1}$ For practical reasons, as some of the students are not Finnish-speaking and as exchange students study with the ITE group, a large part of the instruction is given using English as a lingua franca. The programme follows the structure of regular primary teacher education, but integrates the perspectives supporting intercultural competence and sensitivity into all courses on educational sciences, as well as many other subject areas. The students are encouraged to do their teaching practice in diverse multicultural contexts, and an exchange period abroad (minimum one academic term) is a compulsory part of the programme. It can be assumed that the teachers selected for this study have always been at least to a certain extent 'interculturally oriented', as

they ended up studying in the intercultural teacher education programme. ${ }^{2}$ The stories could be very different if collected from some other teachers. Teachers interviewed for this study can be considered 'early career' teachers, as they had been working for about five years since their graduation. Nine of the ten teachers were female ${ }^{3}$ and they were all about 30 years old at the time of the interviews. 
Methodologically, this study is located in the framework of narrative biographical research (e.g. Clandinin 2007; Goodson and Sikes 2001; Lieblich, TuvalMashiach and Zilber 1998; Riessman 1993, 2002; Spector-Mersel 2010). This article emphasizes that becoming a teacher is a lifelong process that is both a personal and professional one (Elbaz-Luwisch 2005). In particular, a narrative biographical approach enables investigating intercultural learning as a lifelong process: this article argues that the intercultural learning process does not start during a stay in a foreign culture or during teacher education; rather, teachers' attitudes towards diversity, their awareness of cultural, global and societal issues, as well as their skills in encountering diversity, already started to develop in childhood.

The data for this study have been collected by conducting narrativebiographical interviews (Atkinson 2002). All in all, Katri (the first author), ${ }^{4}$ interviewed ten teachers who had been working since their graduation for about five years in various multicultural contexts (such as in the preparatory classes for students with immigrant backgrounds, international schools, immersion classes and ordinary Finnish schools). This study is based on the assumption that all classrooms are diverse: diversity and multiculturalism are understood to refer to dynamic and changing cultural and subcultural characteristics and differences that are part of people's identities (e.g. Nieto 2002, Parekh 2006).

In the interview situation, Katri asked the teachers to give an account of their life story from childhood to the present, with an emphasis on intercultural learning. Before the interview, Katri had asked the teachers to draw a picture that would somehow illustrate the experiences or turning points that had been meaningful for their intercultural and professional learning in various phases of their lives. The interviews proceeded mainly chronologically according to the research subjects' life 
courses, starting from childhood and ending at their future plans. The interviews which were actually more like conversations - lasted from 1.5 hours to three hours each.

First, the content of each life story was analysed through holistic content analysis (Riessman 1993). The preliminary research interest was to study teachers' intercultural learning in general. However, the data-based analysis made it clear that the intercultural experiences that the teachers elaborated in their stories were often charged with strong emotions, even though the teachers were not explicitly asked about emotions in the interviews. Still, when the teachers described their intercultural learning processes, the meaningful and significant experiences that they chose for their stories were often emotionally loaded. Thus, secondly, the focus of analysis moved on to the significance of emotions in the intercultural learning process. Here, Golombek and Doran's (2014) model for identifying emotional content in narrative was loosely applied. For the purposes of this study we selected three of the dimensions by Golombek and Doran for finding the emotional contents in teachers' stories:

(1) The stories include emotional language (emotions are explicitly mentioned).

(2) The stories deal with moral or ethical dilemmas and judgments or there are expressions of idealized beliefs and goals (as emotions are seen as indicators of moral beliefs).

(3) The stories deal with conflict situations (the more relevant a teacher evaluates an incident as being, the more intense the emotional experience). 
On the basis of this model any emotionally loaded experiences, episodes and ideas were looked for from the interviews that were interpreted to have a role in the teachers' intercultural learning. The third analysis phase followed the thematic analysis (see Riessman 2008) of a qualitative study, including coding, finding the themes and reviewing the themes. After finding the significant content and giving them codes, the contents were thematised under wider themes. This thematisation was done for all the interviews separately. Finally, the themes found from individual interviews were compared to themes found in the other interviews and further thematised under four main (more abstract) themes which will be discussed as findings.

The stories chosen for this article relate to the teachers' childhoods and adolescence, experiences in teacher education, free time, and work as a teacher. Although the teachers' stories in this article come from individual and personal experiences, they also represent some more generic phenomena in the data. The extracts chosen for this article were the ones in which teachers were actually able to verbalize what they had learnt.

The teachers have been given pseudonyms. The stories presented were translated from Finnish to English. Unnecessary repetition, words and phrases have been removed in order to improve readability. Certain words and comments have been added to some of the stories [in square brackets] to improve readability.

\section{Findings}

\section{Emotional Experiences Shaking One's Values and Perspectives}


One way that the significance of emotions for intercultural learning appeared in the teachers' stories was when they related an emotionally strong biographical experience that challenged their thinking or values. In general, we could assume that people who have graduated from intercultural teacher education are rather open towards diversity even before commencing their studies. However, regardless of the teachers' backgrounds and living environments, in many of the teachers' biographical stories it appeared that certain kinds of diversity are easier to deal with. For example, religious differences seemed to be difficult for some people to address. In the following example, Niina, who at the time of the interview was working as a teacher in an international school, talks about her experience as an atheist coming to study in teacher education and being a member of a group where some of the students were very religious:

Niina: In our [teacher education] group, some students were really devoted Christians. I was genuinely astonished that they argued that they are critical thinkers, yet at the same time they believe in what I consider mythical creatures. At some point, I realised that some of my fellow-students were really hurt by my views, even though I never intended to hurt anybody. I told them that they were free to criticize or challenge my worldview, and I wouldn't become upset. We should be able to discuss differences constructively as student teachers. They responded that it is better to avoid discussing certain issues because they are too personal and sensitive. That was really confusing to me. I thought - and I still do think - that people should be able to discuss these kinds of difficult issues more openly in order to really understand different ways of thinking; but I do understand now that my approach was maybe too aggressive. After that experience, I have always tried to remember to think twice before I say anything - especially anything related to religion.

The particular emotion that many teachers, including Niina, explicitly mentioned when discussing their intercultural learning was 'confusion'. In the 
learning context, confusion is often framed as a negative, the opposite of 'understanding' (Plaut 2006). However, the way that the teachers in this data discussed confusion was similar to what is conceptualized as a disorienting dilemma in transformative learning: experiencing something that does not fit your expectations and forces you to change your views (Mezirow 1991). Mälkki (2011) argues that disorienting dilemma is first and foremost an emotional matter.

Another example of confusion triggering a learning process is from Tiina, who at the time of the interview was working as a teacher in a regular Finnish primary school. While Niina begun to recognise the significance that religion could have for others during teacher education, for Tiina religion had always been present in her own life. In the following example, she refers to her experience during an exchange year when she was sharing a flat with someone whose sexual orientation was different from her own. This person became a good friend and was significant in affecting Tiina's attitudes towards sexual minorities:

Tiina: We became very close, and she is still a very important person for me. I do respect her, but it was very difficult for me and confusing because according to my conviction it [having a different sexual orientation] was somehow unnatural. It was difficult for me to accept that side of her. But I think it was really great that we talked and talked about it and everything else, and even today I am not quite sure what I think about this issue or what feels right to me. But it opened my eyes - it really opened my eyes. It confused me and it opened my eyes to realize how judgemental this society is towards some groups.

In both the above examples, the teachers impart that their confusion triggered a change in thinking. In Niina's case, it made her critically reflect on her own 'critical approach'. On the basis of Niina's story, it seems that this occasion - being a member of a religiously heterogeneous group in teacher education - actually changed Niina's behaviour to be more tactful and sensitive in similar situations. In Tiina's case, it was 
confusion that she felt which finally made it possible for her to better understand the systematic nature of oppression. Tiina seems to suggest that even though she rationally understands now the inequality related to judging different sexual orientations, at an emotional level she is not sure how she 'feels' about the issue. Zembylas (2007) writes about the possibility of 'ambivalent' emotions for transformation, suggesting that they may imply a possibility for change. In the same way, the 'confusion' that teachers describe in their stories can be considered a starting point and a possibility for making changes in one's views. In general, in the teachers' stories in our data, the confusion often related to certain kinds of diversity or different ways of thinking (e.g. in Niina's case religion, Tiina's case religion and sexual orientation) that, for some reason, were difficult to accept or understand.

The teachers also talked about other types of emotionally powerful experiences that had made them aware of inequality in the world, shaking their whole worldview. The emotions that the teachers explicitly or implicitly described in this regards were 'anger' or sometimes 'being guilty'. When discussing her significant intercultural biographical experiences, Jenni, who at the time of the interview was working as a teacher in a preparatory class for immigrant students, goes back to the time to when she was a teenager:

Jenni: I was sixteen when I first watched Malcolm X [a movie about the American civil rights activist] and after seeing it I just cried. I sat in our living room alone and cried. Of course, I was a teenager with emotional highs and lows, but it affected me so much that I couldn't really think of anything else for a long time. I was angry and sad at the same time, angry at myself and the whole world. I was also angry at my friends who were laughing at my pain, and I was really upset when I asked one of my friends to watch the film and all she had to say after watching it was "it was interesting, but I have seen better ones" [laughing]. After seeing the film, I wrote in my diary that I promise to do my own tiny part to combat inequity. And yes, I have tried to keep that promise. 
Jenni's transformative experience took place in her own living room, while in the next example from Elina, who at the time of the interview was working as a teacher in a language immersion class, the context she talks about is very different, although the emotions seems to be to some extent similar:

Elina: When I was 19, I travelled to South America to do voluntary work. It was really significant for my own growth, and I really had to think about my role there: am I an aid worker or a friend or what? I saw horrible things: starved, sick babies and things like that. In a short time, a lot happened in my head, and my whole world transformed. Up to that point, everything had been easy and nice in my life. It was amazing to see the simple circumstances people were living in. I had terrible diarrhoea in the middle of the night, and I remember walking in the dark and looking for the toilet ... When I came back, I had a transformational feeling. I was looking at people and thinking about how they could just walk like this, so ordinarily. My own life had changed so much. I had difficulties facing people and talking to them in my hometown. I felt their world and also my own former world, so superficial and superfluous - I even stopped wearing jewellery, as I thought that it was so pointless, and every time I went to the toilet I realized, 'Hey, we have the toilet'. It was kind of a holistic change in my life.

Jenni's story in particular includes lot of emotional vocabulary: she talks about crying, emotional highs and lows, and being angry, sad and upset. In both Jenni's and Elina's stories, the feeling of guilt seems to be present, although it is not explicitly mentioned: Jenni talks about being angry at herself, and Elina describes her 'former' life as easy, nice, pointless and superficial. In both of the above stories, the emotions (such as anger and sadness that they explicitly mention) seem to fasten upon the whole world - and its inequity. Batson et al (2007) write about 'moral anger' stemming from being upset over a moral standard being violated when witnessing an unfair act, and they separate it from the kind of anger people sometimes feel when their own interests are thwarted or 'emphatic anger' when someone else's interests are 
thwarted. One could easily claim that these stories are examples of 'emphatic anger' that does not lead to any concrete action. However, both teachers talk about these experiences as being significant and transformative for them as individuals: for Elina, it started a transformation process that she describes as a 'holistic change', while for Jenni, her strong feelings made her decide that she would do her part to fight inequity. In general, in this section, intercultural learning appears as a change in one's own thinking and worldview but also relates to encountering oneself and the other.

\section{From Emotions to Action}

This section describes how emotions led to action in teachers' stories. There is a lot of research (e.g. Berlak 2004; Razack 2007; Zembylas and Chubbuck 2009) that suggests that discomforting feelings (such as anger or feeling guilty, which were discussed in the previous section) are persistently able to block, defuse and distract the transformation of students. On the other hand, unpleasant emotions, such as 'moral anger' as a consequence of witnessing violations of justice, humanity and dignity, have been defined as an essential and powerful emotion in terms of transformation and social change, because they can motivate individuals to act against injustices (Batson et al. 2007; Holmes 2004; Lorde 1984; Lanas and Zembylas 2014; Zembylas 2007). Unpleasant emotions such as anger are assumed to be a potential source of moral motivation, prompting efforts to restore fairness and justice either by compensating the victim or by punishing the harm-doer (Carlsmith, Darley and Robinson 2002; Darley and Pittman 2003).

As described in the previous section of this article, it is not always apparent how emotionally strong experiences affect or promote action. However, there were also stories that demonstrated rather straightforwardly how an emotional reaction led 
to action. Anger was again an emotion explicitly mentioned in this context. The following extract is taken from Riitta's interview. At the time of the interview, she was working as a teacher in a regular Finnish primary school. In the extract, Riitta's anger and the action that followed relate to the schools' politics, which she considers unjust:

Riitta: This particular student [with an immigrant background and special needs; he was not in Riitta's own class but Riitta taught him English] was arbitrarily moved from one group to another many times a year, and finally they decided to transfer him to another school. It seemed to me that the only reason for this was that it made the teachers' work easier. This [decision to transfer the student] made me sad, but also so angry that I decided to talk about the issue with the head teacher and tried to appeal to her that the student could stay in our school. This student had finally made friends in our school, and I had seen him smiling for the first time in two years. She [the head teacher] seemed to understand my worry, but at the same time I could very clearly read between the lines that she considered me to be a new, idealistic teacher who does not understand all the complexities taking place in the school system. I remember clearly how she told me in a very patronizing way, 'Riitta, you are such a good and fair teacher, but you must understand that many of us have been doing this work for dozens of years, and we don't make any decisions without good reasons'.

In this example, Riitta attempted to channel her anger into action. She felt angry because a student was being treated unfairly and decided to do something about the issue. However, the action did not seem to lead anywhere, as Riitta's views collided with those of the other teachers and the head teacher. This was a rather common phenomenon in the teachers' stories: they felt that the school culture and politics did not necessarily support their ways of thinking. All the teachers in this study can be considered as early career teachers, who often have to struggle to find their place in a work community (e.g. Kelchtermans and Ballet 2002; see also Toren 
and Iliyan 2008). Kelchtermans and Ballet (2002) use the concept of micropolitics when referring to the strategies and tactics used by individuals and groups in an organization to further their interests. Micropolitical action can be understood as 'those actions that aim at establishing, safeguarding or restoring the desired working conditions' (Kelchtermans and Ballet 2002, 108). In the case of Riitta, these 'desired working conditions' seemed to be different for Riitta than for the other staff.

In addition to being disappointed and angry at their schools' micropolitics, the teachers sometimes described pain related to their own actions as a teacher and the action that followed the difficult feelings. Aino, who at the time of the interview was teaching a preparatory class for immigrant students, talked about an experience with an immigrant student and her family that was significant for her own professional intercultural learning:

Aino: I heard from one parent that her child was exhausted because of me. I asked too much, gave too much homework, raised too difficult issues. I tried to explain that I had high expectations of all my students and I really did my best to make them learn. But this conversation made me realize that what this mum had said might have been true. All teachers want to be good and do the right things, and then when you realize that you have been doing something that is actually harmful for someone, you feel that you must be a really bad teacher. However, after crying one night and thinking of other career choices [laughing], I decided to try something different [in the classroom]. I consciously started to demand less and encourage more, to spend some time every day with each individual student to ask how they are doing and how they feel, what they had learnt that day, what had been difficult and what they wanted to learn the next day. It was actually an important turning point in my way of teaching, but it was difficult for me to admit that I do make mistakes.

Aino's story is a clear example of how intercultural learning is related to teacher's identity: a teacher really is reflecting here who she is as a teacher (c.f. 
Connelly and Clandinin, 1999). Aino seems to be a reflective teacher who manages to channel the painful experience into a meaningful action 'to try something different' instead of merely blaming students, parents or structures.

In contrast to painful emotions, teachers also referred to many positive emotions when discussing their intercultural learning processes. This is visible in the following story from Jenni (the teacher in a preparatory class for immigrant students) in which she talks about her students (and also the students' parents):

Jenni: I have become so close with them [the students], that when I listen to other teachers in the teachers' room complaining about their horrible students, I very concretely realise that it is not just a teacher-student relationship that we have in my classroom; it is something more. Of course, it is a small group, so it is easier to really get to know them well. Very often they don't have that many Finnish adults in their lives. I may be the only one they know well. I have helped their families who are struggling with Finnish bureaucracy, I have gone to offices with them, I have defended my students in different occasions, even in a police station. I know that officially this is not part of my work, but I just can't turn away from them - I care about them too much.

Several authors have acknowledged love as a compelling political force that has transformative potential in struggles against social injustice and towards social change (Hooks 2000; Daniels 2012; Freire 2004; Lanas and Zembylas 2014; Liston and Garrison 2000). Cultivating emotions such as excitement, love, caring and compassion can begin to inspire teachers and provide them with an alternative 'paradigm' of fighting for more equal practices in school and society (Baumgartner and Johnson-Bailey 2008; Lanas and Zembylas, 2014). For Daniels $(2012,10)$ love in the context of teachers' work means 'a strong and deep commitment to protecting, caring for, and empowering students in the face of social barriers and oppressions that 
surface in their everyday lives, as well as a political passion to inspire and support marginalized youth'. For Jenni, in the previous example, caring extends also outside the classroom, even helping students' parents very concretely in their everyday lives. Daniels (2012) points out that teachers could intentionally learn to recognize and exploit love as a means of motivating the transformation and helping them to make decisions; thus, as a tool for intercultural learning.

\section{Teachers' Own Feelings of Otherness Enabling Sensitivity towards Differences}

This section includes examples in which teachers describe their feelings of otherness or being different related to their biographical stories. Anna, who at the time of the interview was teaching a regular Finnish class, had some painful memories from her childhood:

Anna: I was often left out and really felt like an outsider. I think it was because I was not interested in the same things as most of the girls in my class, and I often felt that there must be something wrong with me because it was so difficult for me to find friends. I sometimes still have nightmares of standing alone in the schoolyard and other students calling me names. I don't want that to happen to my students, and I do my best to prevent any kind of bullying. And I keep repeating all the time to my students that everyone is different and that this is a great thing. I think I am oversensitive to this issue, and I am more than aware of the fact that even though I don't see bullying, it does not mean that it doesn't exist.

Although Anna described these experiences as being painful and said that her sense of being different led to a feeling of inadequacy, she still says that these experiences helped her to recognize and understand diversity and to be sensitive towards differences, and especially towards bullying. In addition to Anna's story, there were numerous other stories in which teachers talked about their own 
experiences of being different or an outsider. The contexts varied from childhood memories from day care to quite current feelings of 'being a different teacher' to others in their schools (see Jokikokko 2005).

An ability to take different perspectives - to look at issues through another person's eyes - is considered to be both a significant condition and an outcome of intercultural learning. In other words, encountering 'otherness' constitutes a crucial part of intercultural learning (Bennett 1993; Deardorff 2008). However, some have also challenged this view. There are philosophers who claim that we are always 'prisoners' of our own culture and unable to achieve a critical distance from it, and therefore understanding others can be impossible (see Boler 1999). The concept of empathy, which is often related to this discussion, is also much debated and complex. Boler (1999) has argued that she 'is not convinced that empathy leads to anything close to justice, to any shift in existing power relations' (p. 157). On the other hand, Kristeva (1992) highlights that one way to learn to recognize diversity is to understand otherness as part of one's own identity.

In the interviews the feeling of otherness sometimes related to personal family issues, as in the next quotation from Sara, who had worked as a substitute teacher in different schools and done other short-term educational tasks. At the time of the interview, she was on maternity leave, taking care of her new-born child:

Sara: When I was expecting my child, I was a bit jealous of other mums-to-be, as they seemed to be so happy and carefree. Of course, I was happy too and loved my unborn child more than anything, but sometimes I was also distressed: how will I ever handle the fact that my child will most likely face at least some discrimination because of his skin colour [ which was different to that of most Finns] ... I just keep on hoping that this world and this society will change. When this issue becomes so close to you, you just can't close your eyes to all the bad things that are happening around you - in schools, as well. 
Sara's story is very emotional. She talks about love and happiness combined with distress. Sara points out that when the experience of inequality or otherness becomes personal, you 'can't close your eyes' anymore. This story from Sara clearly shows how teachers' intercultural learning is an interplay between personal and professional aspects (see Day and Leitch 2001 on teachers' professional learning), and also how the personal and professional intertwine in teachers' stories about their lives (e.g. Clandinin and Huber 2005; Nias 1996).

\section{Emotional Climate Supporting Intercultural Learning}

This section includes stories that highlight the importance of a certain type of emotional atmosphere for teachers' intercultural learning. As mentioned in the theoretical framework of this article, emotions are not just (intra)individual, private and psychological phenomena; they are determined also by relationships and social contexts (e.g. Hargreaves 2001; Zembylas 2007). The data included examples of the significance of a certain type of emotional climate for the teachers' thinking and actions. Juha, at the time of the interview a teacher in an international school, recalls his studies in the ITE programme, and especially the 'spirit' of the programme, in the following way:

Juha: I went through a certain period that some might call idealism ... I think that it was because of the study group that these issues became interesting in a very different way than before. We had a certain spirit there that stirred up some fanatically idealistic and perhaps even nä̈ve thinking at times ... But even though it was rather trancelike at times, I think this spirit was very special. We got support from each other and I think we were rather whole-hearted in our attempts to change things for the better. It was something unique - I haven't experienced anything like it since. 
The story above shows how emotions can be contagious (e.g. Becker, Goetz and Ranelluchi 2014). Bellocchi, Ritchie, Tobin, Sandhu and Sandhu (2013) use the term emotional climate to refer to the joint emotional arousal, collective identity formation and reduced sense of self taking place in a group. Juha describes the emotional climate of his study group in teacher education by using rather strong terms such as 'fanatic' and 'trancelike', and he seems to suggest that it was the emotional nature of the group that really affected him and other members of the group.

Another example of the significance of the emotional climate is from Emma, who at the time of the interview was teaching a preparatory class for immigrant students. She does not want to share her feelings with other teachers (teaching regular Finnish classes) in her school, because she feels that they would misinterpret her. She 'feels safe' with other teachers of immigrant students and get support for her professional intercultural learning from them:

Emma: I have become even more aware of the fact that the less people know about immigrants, the more insecure they are. They [the other teachers in the school] don't dare to get close or talk to them. They don't know what to say or whether the other person will understand what they say ... The meetings with other teachers of immigrants have become very important because I don't want to talk about my worries and problems [relating to the students] with other teachers [in the same school], as they would then have even more reasons to be shocked and horrified by my students ... With these other teachers of preparatory classes, I feel safe to talk about these [issues] and I know that they understand and we can give each other constructive guidelines on how to improve our students' situations and learning.

Both Juha's and Emma's stories emphasise the importance of groups and social networks that share similar ideas and ideals; these networks seemed to be significant conditions for teachers' intercultural learning partly because of the positive 
emotional climate. It is important for people to feel that they are not alone with their ideas and feelings.

\section{Discussion: Implications for Developing Intercultural Learning as an Emotional Process in Teacher Education}

Meaningful intercultural experiences are emotionally charged, and thus there is an argument that emotions are inevitably present in the intercultural learning processes. However, emotions have more often been seen as a hindrance than as a possibility for intercultural learning. The significance of emotions in teachers' biographical stories about their intercultural learning has not been given much attention in the previous research literature. This article has shown how ten teachers described the significance of emotions in their intercultural learning in different phases of their lives and work. Emotions were significant in questioning their worldview, ways of thinking, and actions towards more just practices. The significance of emotions in intercultural learning was also present when teachers discussed how their own feelings of otherness made them sensitive to differences and how other people's emotions affected their intercultural learning (the significance of the emotional climate). The teachers' stories clearly show how the personal and professional lives of teachers and their experiences intertwine in their intercultural learning processes. Sometimes, a single particular moment in a teacher's personal life or work can be important for their intercultural learning, while sometimes it is a longer period of life (such as teacher education or a friendship). The article suggests, on the basis of the teachers' stories, that emotions can function as a potential resource, a growth point or a premise in the intercultural learning process. This article also 
shows how the personal, professional and emotional aspects in teachers' intercultural learning intertwine, based on ten teachers' stories.

Boler (1999) reminds us that "emotions are inseparable from actions and relations, from lived experience' (p. 2). This should also be acknowledged more when thinking about how to support teachers' intercultural learning in teacher education. Previous studies have often pointed out that teachers are expected to leave their emotions outside the classroom, even though doing so is impossible in reality (e.g. Britzman 1998). Due to the rather one-sided rational emphasis in teacher education, both teacher educators and students may be uncomfortable talking about emotions (Weinstein and Obear 1992). The old myth of expressing and discussing emotions being a sign of unprofessionalism and that teachers need to manage their own emotions and control the emotional expressions of their students is still strong in the minds of many (Boler 1999; Schutz and Zembylas 2009). Thus, the first step in teacher education should be to acknowledge the significance of emotions in learning in general, and intercultural learning in particular, by recognizing the professional self as both a thinking and feeling actor.

As this article demonstrates, facing and discussing issues of cultural diversity, discrimination and inequality may require learners to engage in demanding and discomforting learning processes. Several authors recognize in different ways the pain involved in these types of transformation processes (Lanas and Kiilakoski 2013; see Tarc 2013) - the same pain that was also visible in the teachers' stories in this article. Boler (1999) has introduced the concept of the pedagogy of discomfort, implying that growth and change do not typically come without a crisis. She suggests that crisis is something that is necessary for 'being a teacher'. Pedagogically, this approach assumes that discomforting emotions have a constitutive role in challenging dominant 
beliefs, normative practices and social habits that sustain social inequities, and in creating the possibilities for individual and social transformation (Zembylas 2012). Such a pedagogy has as its aim to uncover and question the deeply embedded emotional dimensions that frame and shape our daily habits and routines, and to deconstruct the ways in which we have learned to see, feel and act (Boler and Zembylas 2003). Zembylas $(2012,2015)$ asks how appropriate or ethical it is to engage students in pedagogical activities that create discomforting situations. Teachers in the data used in this article said that their own feelings of otherness and being an outsider (or being bullied) had made them more sensitive towards diversity. Would it be ethical (or possible) to create for teachers these type of experiences of marginalization during teacher education? There is no simple answer to this question, but the literature acknowledges certain necessary conditions for implementing pedagogy intended to transform students' views (Zembylas 2012, 2015; Meijer 2011; Jokikokko 2010).

Meijer (2011) emphasizes safety as an important condition when dealing with emotionally strong experiences, such as confusion or anger and going outside the comfort zone in teacher education. It is important to create a learning environment that guarantees safety, trust and openness within the learning group and between group members and teacher educators. In this kind of environment, there is space for reflection, discussion and debate without the fear of being judged or embarrassed. On the other hand, Boler and Zembylas (2003) argue that there are no safe classroom spaces, as the conditions of power and privilege always operate in them. However, they also emphasize that, despite these power imbalances, it is possible to create some sort of safety (including commitment, responsibility and compassion from the students and teacher educators alike), even under discomforting conditions. An ethic 
of empathy and care is necessary to provide a safe place for students in which to examine and challenge their assumptions and beliefs. This article points out the importance of the emotional climate of a student teachers' learning group. Teacher educators should think of various ways to address and exploit this emotional intensity in the group, which seems to be relevant to students' learning and sense of membership.

As became obvious from the teachers' biographical stories in this article, intercultural learning is often an informal process affected by various phases and incidents of life, and the most significant learning experiences will not take place within the lecture halls of academic institutions. That is why student teachers should be offered opportunities to gain learning experiences in multiple environments, including outside their comfort zone. If teacher educators wish to encourage activism, they have to create spaces that facilitate the ways in which students can recognize, address and act on their emotions, and through that affect social injustices (see Zembylas 2012). For instance, teaching practices in various multicultural contexts, service learning and other types of voluntary work can offer opportunities not only for critical emotional reflection, but also for concrete action. In the context of in-service education, various mentoring practices could help teachers to recognize their emotional states related to injustice in their thinking and practice and actively work to change these practices.

The learning methods of teacher education could also be reconsidered from the perspective of emotions in order to help student teachers to identify their own emotions and emotional states as well as the role of emotions in the power relations within a classroom and society at large (Zembylas and Chubbuck 2009). It is important to offer opportunities for student teachers to critique the reproduction of 
inequality and engage in practices that inspire imagination and emotions, such as excitement for a more fair and just world (Zembylas 2009). Lupton (1998) suggests that people often feel emotions at the unconscious rather than conscious level of experience. In order to trigger emotionally powerful experiences, becoming more aware of them, and to reflect on and engage in dialogue with one's emotional experiences, Dirkx (2006) encourages educators to selectively utilize fiction, poetry and films related to the overall focus of the learning group (e.g. social justice/injustice) and ask students to maintain a personal journal (free writing) on their experiences. With increased awareness, student teachers are more able to create congruence between their affective states and their conceptual sense-making. These types of methods can also help learners to bridge cultural differences by affording glimpses into others' worlds of felt experience, thus creating pathways for empathic connection (Dirkx 2006; Lupton 1998). Although this article presented an example of how significant the experience of watching a film can be, Boler (1999) emphasizes that the mere experience, e.g. reading a 'multicultural' text (or watching a film) and reflecting upon it in a journal, is not necessarily conducive to any constitutive change in consciousness. That is why students should be engaged in self-reflective participation and active reading practice that involves challenging their assumptions and worldviews; students should engage themselves with the dilemmas cited in the text (or e.g. film) instead of viewing them in a passive way.

This article speaks strongly against standards-based teacher education focusing on clearly measurable outcomes and assessment (e.g. Hattie, 2012). Instead, we argue that the reflective work on student teachers' identities as future teachers which enables them to gain insights and knowledge of themselves and their own values should be emphasized in teacher education. This type of reflection is necessary 
if we want to educate teachers who are able to respect and respond to growing diversity of student and promote social justice in schools and society.

\section{Notes}

\footnotetext{
${ }^{1}$ In Finland, a primary school teacher qualification includes a five-year master's degree with a strong research base.

${ }^{2}$ Teacher education is very popular in Finland. Only about 10 per cent of those who apply for the ITE programme are accepted. Twenty new students are selected for the ITE programme every year. The selection criteria emphasize interest, motivation and the potential to study intercultural issues. ${ }^{3}$ There are only a few male students studying in each ITE group. In general, females are in the majority in Finnish primary school teacher education.

${ }^{4}$ Minna (the second author) became involved in the study during the process of writing the article.
}

\section{References}

Atkinson, R., 2002. “The Life-Story Interview.” In Handbook of Interview Research: Context and Method, edited by J.F. Gubrium and J.A. Holstein, 121-140. California: Sage Publications.

Batson, C. D., C. L. Kennedy, L-A. Nord., E. L. Stocks, D. A. Fleming, C. M. Marzette, D. A. Lishner, R. E. Hayes, L. M. Kolchinsky and T. Zerger. 2007. "Anger at Unfairness: Is it Moral Outrage?" European Journal of Social Psychology, 37, 1272-1285.

Baumgartner, L.M. 2001. “An Update on Transformational Learning Theory.” In The New Update on Adult Learning Theory, edited by S. B. Merriam, 15-24. San Francisco, CA: Jossey-Bass.

Baumgartner, L. and J. Johnson-Bailey. 2008. "Fostering Awareness on Diversity and Multiculturalism in Adult and Higher Education." New Directions for Adult and Continuing Education. Special Issue: Adult Learning and the Emotional Self $120,45-53$

Becker, T., V. Goetz, J. Morger, and J. Ranellucci 2014. "The Importance of Teachers' Emotions and Instructional Behavior for Their Students' Emotions - 
an Experience Sampling Analysis. 'Teaching and Teacher Education, 43, 1526.

Bennett, M. 2009. "Defining, Measuring, and Facilitating Intercultural Learning: A Conceptual" Introduction to the Intercultural Education Double Supplement. Intercultural Education 20(4), 1-13.

Bennett, M. 1993. "Towards Ethnorelativism: A Developmental Model of Intercultural Sensitivity." In Educating for the Intercultural Experience, edited by R.M. Paige, 21-71. Yarmouth: Intercultural Press.

Bellocchi, A., S. Ritchie, K. Tobin, M. Sandhu, and S. Sandhu. 2013. Exploring Emotional Climate in Preservice Science Teacher Education. Cultural Studies of Science Education.

Berlak, A. 2004. "'Confrontation and Pedagogy: Cultural Secrets and Emotion in Antioppressive Pedagogies." Democratic Dialogue in Education: Troubling Speech, Disturbing Silence, edited by M. Boler, 123-44. New York: Peter Lang.

Boler, M. 1999. Feeling Power: Emotions in Education. New York: Routledge.

Boler, M., and M. Zembylas. 2003. "Discomforting Truths: The Emotional Terrain of Understanding Differences" In Pedagogies of Difference; Rethinking Education for Social Justice, edited by P. Tryfonas, 110-136. New York: Routledge.

Bierema, L. 2008. "Adult Learning in the Workplace: Emotion Work or Emotion Learning?" New Directions for Adult and Continuing Education. Special Issue: Adult Learning and the Emotional Self 120, $55-64$. 
Britzman, D. P. 1998. Lost Subjects, Contested Objects: Toward a Psychoanalytic Inquiry of Learning. Albany: State University of New York Press.

Bullough, R. V. 2009. "Seeking Eudaimonia: The Emotions in Learning to Teach and to Mentor." Advances in Teacher Emotion Research, edited by P. A. Schutz and M. S. Zembylas, 33-53. Dordrecht: Springer.

Byram, 1997. Teaching and assessing intercultural communicative competence. Multilingual Matters, Clevedon.

Callahan, J. L. 2004. "Breaking the Cult of Rationality: Mindful Awareness of Emotion in the Critical Theory Classroom.” New Directions for Adult and Continuing Education, 102, 75-83.

Carlsmith, K. M., J. M. Darley, and P.H. Robinson, 2002. "Why Do We Punish? Deterrence and Just Deserts as Motives for Punishment." Journal of Personality and Social Psychology, 83, 284-299.

Clandinin, D. J. 2007. Handbook of Narrative Inquity: Mapping a Methodology. Thousand Oaks, California: Sage Publication.

Clandinin, D. J., and M. Huber, (2005). "Shifting stories to live by. Interweaving the personal and professional in teachers' lives". In Teacher professional development in changing conditions, edited by D. Beijaard, P. C. Meijer, G. Morine-Dershimer, \& H. Tillema, 43-59. Dordrecht, Netherlands: Springer.

Connelly, F.M. and D.J. Clandinin, (1999). Shaping a Professional Identity: Stories of Educational Practice. New York: Teachers College Press.

Daniels, E. 2012. Fighting, Loving, Teaching: An Exploration of Hope, Armed Love and Critical Urban Pedagogies. Rotterdam: SensePublishers. 
Darley, J. M. and T.S. Pittman, 2003. "The Psychology of Compensatory and Retributive Justice.” Personality and Social Psychology Review. 7(4), 324-336.

Day, C. and R. Leitch, 2001. 'Teachers' and Teacher Educators' Lives: the Role of Emotion." Teaching and Teacher Education, 17 (4), 403-415.

Deardorff, D. K. 2008. Intercultural Competence: A Definition, Model and Implications for Education Abroad. In Developing Intercultural Competence and Transformation: Theory, Research and Application in International Education, edited by V. Savicki, 32-52. Sterling, VA: Stylus.

Deardorff, D.K. 2006. "Identification and Assessment of Intercultural Competence as a Student Outcome of Internationalization." Journal of Studies in International Education 10 (3), 241-246.

Dirkx, J. 2006. "Engaging Emotions in Adult Learning: A Jungian Perspective on Emotion and Transformative Learning." New Directions for Adult and Continuing Education 109, 15-26.

Elbaz-Liwisch, F. 2010. "Writing and Professional Learning: the Uses of Autobiography in Graduate Studies in Education”. Teachers and Teaching: Theory and Practice 16 (3), 307-327.

Elbaz-Luwisch, F. 2005. Teachers' voices: Storytelling and Possibility. Greenwich, CT: Information Age Publishing Inc.

Freire, P. 2004. Pedagogy of Indignation. Boulder: Paradigm.

Freire, P. 1998. Teachers as Cultural Workers. Letters to Those Who Dare Teach. Colorado: Westview press.

Freire, P. 1972 Pedagogy of the Oppressed. London: Sheed \& Ward. 
Gay, G. 2000. Culturally Responsive Teaching: Theory, Research and Practice. NY: Teachers' College Press.

Golombek, P. R., and M. Doran, 2014. "Unifying Cognition, Emotion, and Activity in Language Teacher Professional Development." Teaching and Teacher Education, 39, 102-111.

Hattie, J. A. C. (2012). Visible learning for teachers. Maximizing impact on achievement. Oxford, UK: Routledge.

Hargreaves, A. 2001. "Emotional Geographies of Teaching." Teachers College Record 103 (6): 1056-1080.

Heikkinen, H. (1998). Becoming yourself through narrative: Autobiographical approach in teacher education. In R. Erkkila, A. Willman, and L. Syrjala (Eds.),

Promoting teachers 'personal and professional growth (pp. 111-131). Oulu:

Oulu University Press

Holmes, M. 2004. "Introduction. The Importance of Being Angry: Anger in Political Life.” European Journal of Social Theory, 7, 123-132.

Hooks, B. 2000. All About Love: New Visions. New York: William Morrow and Company, Inc.

Jokikokko K. 2010 Teachers' intercultural learning and competence. (Doctoral dissertation). Oulu: Acta Universtitatis Ouluensis E 114.

Jokikokko, K. 2005. The Role of Significant Others in the Intercultural Learning of Teachers. Journal of Research in International Education, 8(2), 143-164.

Jones, R. M. 1968. Fantasy and Feeling in Education. New York: HarperCollins. 
Kelchtermans, G., and K. Ballet, 2002. "The Micropolitics of Teacher Education: a Narrative-Biographical Study on Teacher Socialization.” Teaching and Teacher Education, 18(1), 105-120.

Kristeva, J. 1992. Muukalaisia Itsellemme. (Translated P. Malinen Etrangers à nous-mêmes) Helsinki: Gaudeamus.

Lanas, M. and T. Kiilakoski. 2013. "Growing Pains: Teacher Becoming a Transformative Agent." Pedagogy, Culture and Society 21(3), 343-360.

Lanas, M. and M. Zembylas. 2014. "Towards a Transformational Political Concept of Love in Critical Education." Studies in Philosophy and Education. 33(3), 31-44. doi:10.1007/s11217-014-9424-5

Landis, D., M. Bennett, and J. Bennett. 2004. Handbook of Intercultural Training. London \& New Delhi: Sage.

Lieblich, A. and R. Tuval-Mashiach. and T. Zilber. 1998. Narrative Research: Reading, Analysis and Interpretation. California: Thousand Oaks.

Liston, D., and J. Garrison eds. 2004. Teaching, Learning, and Loving: Reclaiming Passion in Educational Practice. New York: Routledge Falmer.

Lorde, A. 1984. Sister outsider: Essays and Speeches. Trumansburg, NY: The Crossing Press.

Lupton, D. 1998. The Emotional Self: A Sociocultural Explanation. Thousand Oaks, California: SAGE.

McLaren, P. 2001. “Teaching Against Globalisation and the New Imperialism: Toward a Revolutionary Pedagogy." Journal of Teacher Education, 52(2), 136-150. 
Meijer, P. C. 2011. The Role of Crisis in the Development of Student Teachers' Professional Identity". In Navigating in Educational Contexts Identities and Cultures in Dialogue, edited by A. Lauriala, R. Rajala, H. Ruokamo and O. Ylitapio-Mäntylä, 41-54. Rotterdam: Sense Publishers.

Mezirow, J. 2009. "Transformative Learning Theory". In Transformative Learning in Practice: Insights from Community, Workplace, and Higher Education, edited by E. W. Taylor and associates, 18-32. San Francisco: Jossey-Bass, cop.

Mezirow, J. 1991. Transformative Dimensions of Adult Learning. San Fransisco: Jossey-Bass.

Min Shim, J. 2012: “Exploring How Teachers' Emotions Interact with Intercultural Texts: a Psychoanalytical Perspective”. Curriculum Inquiry 42:4.

Mälkki, K. 2011. "Theorizing the Nature of Reflection. Doctoral Dissertation.” University of Helsinki, Institute of Behavioural Sciences. Studies on Behavioural Sciences, 238.

Mälkki, K. 2010. “Building on Mezirow’s Theory on Transformative Learning. Theorising the Challenges to Reflection." Journal of Transformative Education 8(1), 42-62.

Nias, J. 1996. "Thinking about feeling: the emotions in teaching." Cambridge Journal of Education, 26 (3), 293-306.

Nieto, S. 2005. "Schools for a New Majority: the Role of Teacher Education in Hard Times." The New Educator, 1(1), 27-43. 
Nieto, S. 2002. Language, Culture, and Teaching: Critical Perspectives for a New Century (a Compilation of Previously Published Journal Articles and Book Chapters). Mahwah, NJ: Lawrence Erlbaum Associates Publishers.

Parekh, B. 2006. Rethinking Multiculturalism. Cultural Diversity and Political Theory $2^{\text {nd }}$ ed. NY: MacMillan.

Plaut, S. 2006." “I Just Don't Get It": Teachers' and Students' Conceptions of Confusion and Implication for Teaching and Learning in the High School English Classroom.” Curriculum Inquiry, 36(4), 391-421.

Razack, S. 2007. "Stealing the pain of others: Reflections on Canadian Humanitarian Responses." The Review of Education, Pedagogy, and Cultural Studies 29: 375-394.

Riessman, C. K. 2008. Narrative methods for human sciences. Los Angeles: Sage Publications.

Riessman, C.K. 1993. Narrative Analysis. Newbury Park California: Sage

Riessman, C.K. 2002. "Analysis of personal narratives." In Handbook of interview research: Context \& method. Edited by Gubrium, J. and Holstein, J. Newbury Park California: Sage.

Rogers, C. R. 1969. Freedom to Learn. Columbus, Ohio: Charles E. Merrill.

Schutz, P., and M. Zembylas. 2009. "Introduction to Advances in Teacher Emotion Research: the Impact on Teachers' Lives" In Advances in Teacher Emotion Research: The impact on Teachers' lives, edited by Schutz, P. A. and Zembylas M., 3-11. Dordrecht: Springer.

Sleeter, C. E. 2010. "Culturally Responsive Pedagogy: A reflection.” Journal of Praxis in Multicultural Education 5(1), 116-119. 
Solomon, R.C. 1990. A Passion for Justice. New York: Addison Wesle.

Spector-Mersel, G. (2010). "Narrative Research: Time for a Paradigm." Narrative Inquiry. 20(1), 204-224.

Tarc, A.M. 2013. “'I Just Have to Tell You': Pedagogical Encounters into the Emotional Terrain of Learning." Pedagogy, Culture \& Society, 21(3), $383-402$.

Taylor, E. 2007. “An Update of transformative learning theory: a critical review of the empirical research (1999-2005)" International Journal of Lifelong Education, 26(2), 173-191.

Taylor, E. 1998. "The Theory and Practice of Transformative Learning. A Critical Review." Information Series No 374. Ohio: ERIC Clearinghouse on Adult, Career, and Vocational Education.

Taylor, E. 1994.” A Learning Model for Becoming Interculturally Competent.” International Journal of Intercultural Relations, 18, 389-408.

Taylor, L. 2011. "Beyond Paternalism: Global Education with Preservice Teachers as a Practice of Implication”. In Postcolonial perspectives on global citizenship education, edited by V. Andreotti and L.M.T.M. de Souza, 177-199. N.Y.: Routledge.

Toren, Z. and S. Iliyan, 2008. "The problems of the beginning teacher in the Arab schools in Israel." Teaching and Teacher Education, 24(4), 10411056. 
Uitto, M., K. Jokikokko and E. Estola. 2015. Virtual special issue on teachers and emotions in Teaching and teacher education (TATE) in 1985-2014. Teaching and Teacher Education. 50, 124-135.

Wang, H. 2012. "Red Eyes": Engaging Emotions in Multicultural Education". Multicultural Perspectives 10(1), 10-16.

Weinstein, G., and K. Obear. 1992. "Bias Issues in the Classroom. Encounters with the Teaching Self'. New Directions for Teaching and Learning. 52: $39-50$.

Zembylas, M. 2015. "Pedagogy of Discomfort and its Ethical Implications. The Tensions of Ethical Violence in Social Justice Education.” Ethics and Education, 10(2), 163-174.

Zembylas, M. 2012. "Manifestations of Greek-Cypriot Teachers' Discomfort toward a Peace Education Initiative: Engaging with Discomfort Pedagogically". Teaching and Teacher Education 28(8), 1071-1082.

Zembylas M. 2008. "Engaging with Issues of Cultural Diversity and Discrimination through Ciritical Emotional Reflecivity in Online Learning." Adult Education Quarterly 59 (1), 61-82.

Zembylas, M. 2007. "Emotional Ecology: The Intersection of Emotional Knowledge and Pedagogical Content Knowledge in Teaching”. Teaching and Teacher Education. 23, 355-367.

Zembylas, M., and S. Chubbuck. 2011. "Growing Immigration and Multiculturalism in Europe: Teachers' Emotions and the Prospects of Social Justice Education”. In International Handbook on Teacher and School Development, edited by C. Day, 293-316. New York: Routledge. 
Zembylas M., and S. Chubbuck. 2009. "Emotions and Social Inequalities: Mobilizing Emotions for Social Justice Education”. In Advances in Teacher Emotion Research: The Impact on Teachers' lives, edited by O.A. Schutz and M. Zembylas, 343-370. London: Springer Science + Business Media.

Zembylas, M. and C. McGlynn. 2013. "Discomforting Pedagogies: Emotional Tensions, Ethical Dilemmas and Transformative Possibilities”. British Educational Research Journal. 38(1), 41-59.

Zembylas, M., C. Charalambous, P. Charalambous and P. Kendeou. 2011. "Promoting Peaceful Coexistence in Conflict-ridden Cyprus: Teachers' Difficulties and Emotions towards a New Policy Initiative.” Teaching and Teacher Education 27 (2), 332-34 